\title{
Thyroid Cancer pT4a Anaplastic Carcinoma TNM Finding v7
}

National Cancer Institute

\section{Source}

National Cancer Institute. Thyroid Cancer pT 4a Anaplastic Carcinoma TNM Finding v7. NCI Thesaurus. Code C89151.

Intrathyroidal anaplastic carcinoma. (from AJCC 7th Ed.) 